NBER WORKING PAPER SERIES

\title{
A FUNDAMENTAL ENFORCEMENT COST ADVANTAGE OF THE NEGLIGENCE RULE OVER REGULATION
}

\author{
Steven Shavell \\ Working Paper 18418 \\ http://www.nber.org/papers/w18418 \\ NATIONAL BUREAU OF ECONOMIC RESEARCH \\ 1050 Massachusetts Avenue \\ Cambridge, MA 02138 \\ September 2012
}

I thank Jennifer Arlen, Ryan Bubb, Louis Kaplow, Henrik Lando, Peter Menell, Geoffrey Miller, A. Mitchell Polinsky, Richard Posner, and David Rosenberg for comments, Minal Caron, Sarah M. Evans, and James McGinnis for research assistance, and the John M. Olin Center for Law, Economics, and Business at Harvard Law School for research support. The views expressed herein are those of the author and do not necessarily reflect the views of the National Bureau of Economic Research.

NBER working papers are circulated for discussion and comment purposes. They have not been peerreviewed or been subject to the review by the NBER Board of Directors that accompanies official NBER publications.

(C) 2012 by Steven Shavell. All rights reserved. Short sections of text, not to exceed two paragraphs, may be quoted without explicit permission provided that full credit, including $\odot$ notice, is given to the source. 
A Fundamental Enforcement Cost Advantage of the Negligence Rule over Regulation

Steven Shavell

NBER Working Paper No. 18418

September 2012

JEL No. K13,K20,L5

\begin{abstract}
$\underline{\text { ABSTRACT }}$
Regulation and the negligence rule are both designed to obtain compliance with desired standards of behavior, but they differ in a primary respect: compliance with regulation is ordinarily assessed independently of the occurrence of harm, whereas compliance with the negligence rule is evaluated only if harm occurs. It is shown in a stylized model that because the use of the negligence rule is triggered by harm, the rule enjoys an intrinsic enforcement cost advantage over regulation. Moreover, this advantage suggests that the examination of behavior under the negligence rule should tend to be more detailed than under regulation (as it is).
\end{abstract}

Steven Shavell

Harvard Law School

1575 Massachusetts Avenue

Hauser Hall 508

Cambridge, MA 02138

and NBER

shavell@law.harvard.edu 


\title{
A Fundamental Enforcement Cost Advantage Of the Negligence Rule over Regulation
}

\author{
Steven Shavell ${ }^{*}$
}

Regulation and the negligence rule are both designed to obtain compliance with desired standards of behavior, but they differ in a primary respect: compliance with regulation is ordinarily assessed independently of the occurrence of harm, whereas compliance with the negligence rule is evaluated only if harm occurs. It is shown in a stylized model that because the use of the negligence rule is triggered by harm, the rule enjoys an intrinsic enforcement cost advantage over regulation. Moreover, this advantage suggests that the examination of behavior under the negligence rule should tend to be more detailed than under regulation (as it is).

\section{Introduction}

Regulation and the negligence rule are both intended to achieve compliance of behavior with desired standards, but they differ in a basic regard. Under regulation, compliance with standards tends to be assessed before, or independently of, the occurrence of harm — conformance with speed limits, fire safety codes, financial regulations, and the like is usually evaluated whether or not harm has eventuated. ${ }^{1}$ Under the negligence rule, in contrast, conformity with legal standards is ordinarily examined only on the condition that harm transpires_-only if car accidents, fires, or financial losses actually come about. ${ }^{2}$

The main point to be developed here is that because the negligence rule is triggered by harm, the rule enjoys a fundamental enforcement advantage over regulation. The advantage flowing from this characteristic of the negligence rule often renders the

\footnotetext{
* Samuel R. Rosenthal Professor of Law and Economics, Harvard Law School. I thank Jennifer Arlen, Ryan Bubb, Louis Kaplow, Henrik Lando, Peter Menell, Geoffrey Miller, A. Mitchell Polinsky, Richard Posner, and David Rosenberg for comments, Minal Caron, Sarah M. Evans, and James McGinnis for research assistance, and the John M. Olin Center for Law, Economics, and Business at Harvard Law School for research support.

${ }^{1}$ This characterization of regulation describes how regulation is generally enforced. See, for example, Posner (2010, ch. 13). But there are some settings in which the occurrence of harm could lead to an investigation of compliance with regulation (even though compliance could also be examined independently of the occurrence of harm). This possibility is discussed in Section 4.

${ }^{2}$ See, for example, Keeton, et al (1984), p. 165, stating that a necessary element of a cause of action for negligence is “[a]ctual loss or damage resulting to the interests of another”; and Dobbs (2000), p. 258, observing that "no claim for negligence will be recognized unless the plaintiff suffers actual harm."
} 
rule a cheaper, more efficient method of enforcing socially desired behavior than regulation.

Moreover, just because of the enforcement cost advantage of the negligence rule, it will frequently be economic for the assessment of behavior under the rule to be more detailed than under regulation. This corollary conclusion may help to explain why in fact the negligence determination is case-specific and usually more thorough than the regulatory—why, for example, a court's inquiry whether a fire at a restaurant was caused by negligence will typically encompass a greater number of considerations than those addressed by fire safety codes.

In Sections 2 and 3 of this article, I analyze the enforcement cost advantage of the negligence rule over regulation employing a stylized model of law enforcement. ${ }^{3}$ In particular, I suppose that there is a single type of behavior that society wishes to control, and I make several assumptions that place regulation and the negligence rule on a level playing field in all but one regard. Notably, I presume that the ability of both regulators and of courts to assess compliance with standards is perfect and that the cost of assessing compliance per instance is the same for each. These assumptions assure that the only difference between regulation and the negligence rule in the model is that the use of the negligence rule is occasioned by harm. ${ }^{4}$

I first compare regulation and the negligence rule supposing for simplicity that compliance with regulation is assessed with certainty. Hence, the cost of verifying compliance with regulation is incurred for sure. Under the negligence rule, however, the cost of evaluating compliance is experienced only with the probability that harm occurs. Consequently, the negligence rule clearly involves lower enforcement costs than regulation. ${ }^{5}$

\footnotetext{
${ }^{3}$ Section 2 is informal, but contains numerical examples; Section 3 is formal.

${ }^{4}$ These assumptions are not made because I believe that they are realistic; the ability of regulators and of courts to assess behavior may not be the same in fact, and so may other factors of relevance to the comparison of regulation and the negligence rule vary, as I will occasionally observe. But one must abstract from all such differences in the analysis proper if one is to isolate the importance of the characteristic of the negligence rule that it, but not regulation, is triggered by harm.

${ }^{5}$ In the analysis, I consider, as I must, the effectiveness of regulation and of the negligence rule in achieving compliance. In particular, I show that even though compliance is examined only with a probability under the negligence rule, it will result in compliance under broad assumptions.
} 
I then compare regulation and the negligence rule allowing for regulation to be enforced probabilistically. Under this assumption, enforcement expenses under regulation can be saved. Even so, I demonstrate that the negligence rule possesses an enforcement cost advantage over regulation. ${ }^{6}$ To illustrate, consider the case in which compliance with a standard eliminates all possibility of accidents-suppose that installation of a sprinkler system at a restaurant would eliminate any chance of harm to individuals from a fire. Then the negligence rule would involve no costs, as no firecaused injuries would occur. But regulation would necessarily involve costs, for there would have to be a positive probability of verification of compliance with regulatory standards to induce the installation of sprinkler systems. More generally (when compliance with a standard does not eliminate all possibility of accidents), the superiority of the negligence rule will be seen to rest on the observation that under the rule, compliance with a standard reduces the number of instances in which behavior is examined, whereas under regulation, compliance with a standard does not reduce the number of instances in which behavior is examined (installation of a sprinkler system does not lower the frequency of monitoring).

In Section 4, I discuss and interpret the conclusion from the model that the negligence rule possesses a principal enforcement cost advantage over regulation. Here I consider the following points, among others. First, an implication of the enforcement advantage of the negligence rule is, as I noted at the outset, that it will desirable for society to control more dimensions of behavior under the negligence rule than under regulation. Second, despite the enforcement cost advantage of the negligence rule in the model, regulation may be preferred to the rule for reasons going outside the model, especially because of the judgment proof problem and difficulties in establishing causation of harm (both of which dilute the threat of liability for negligence). Consequently, in theory as in reality, it will generally be desirable for society to employ regulation along with the negligence rule. Relatedly, given that regulation and the

\footnotetext{
${ }^{6}$ The argument takes into account that regulation and the negligence rule must be enforced sufficiently frequently that compliance under them is achieved. Because the minimum probability of enforcement that achieves compliance is influenced by the maximum possible sanction for noncompliance, I assume that the maximum possible sanction is the same under regulation and under the negligence ruleotherwise one legal regime would possess an arbitrary enforcement advantage over the other.
} 
negligence rule ought to and do co-exist, the question arises whether satisfaction of regulation should insulate a party from liability for negligence. The answer given is no, essentially because of the first point, that it will not be economic for regulators to evaluate as many dimensions of behavior as the courts.

Before proceeding, let me note that there exists prior economically-oriented writing on regulation versus liability. ${ }^{7}$ This literature emphasizes factors other than enforcement costs, ${ }^{8}$ although the point that liability may have an enforcement cost advantage over regulation is adumbrated there. ${ }^{9}$ I should also state that my purpose here is not to canvass and weigh the various advantages and disadvantages of regulation versus liability, but rather to focus on the specific factor of enforcement costs.

\section{A Model of Enforcement of Regulation and the Negligence Rule}

Assume that there is a precaution that a potential injurer ${ }^{10}$ can take that would lower the risk of harm but that involves a cost. For concreteness, imagine as above that the precaution is installation of sprinklers in restaurants, and assume that a sprinkler system would reduce the long-term risk of a fire at a restaurant from $4 \%$ to $1 \%$, that a fire would cause harm of $\$ 100,000$, and that a sprinkler system would cost $\$ 2,000$.

Suppose that the social goal is to induce a precaution whenever the benefit it would yield — a reduction in expected harm—would outweigh its costs — comprised of the cost of the precaution itself and of the costs of law enforcement. ${ }^{11}$ In the example of the sprinklers, the benefit of the precaution would be $\$ 3,000$, for a sprinkler system would

\footnotetext{
${ }^{7}$ See Shavell (1984a, b) and Wittman (1977); and see also Kolstad, Ulen, and Johnson (1990) and the collection of articles in Kessler (2011a), particularly Posner (2011) and Shleifer (2011).

${ }^{8}$ As Kessler (2011b) notes in his summary of the literature, the factors that are examined include rules versus standards, the judgment proof problem, imperfect judicial decisionmaking and incentives, and matters of political economy.

${ }^{9}$ See my remarks in Shavell (1984a, p. 364), mentioning that liability may enjoy an advantage because it applies only with a probability.

${ }^{10}$ I will often refer to a potential injurer simply as an injurer even though the "injurer" may not in fact cause harm.

${ }^{11}$ Equivalently, the social goal is to induce a precaution whenever it would lower total social costs, equal to the sum of expected harm, the cost of the precaution, and the costs of law enforcement.
} 
lower expected harm from $4 \%$ x $\$ 100,000$ or $\$ 4,000$, to $1 \%$ x $\$ 100,000$ or $\$ 1,000$. $^{12}$ Because the cost of a system is $\$ 2,000$, it would be desirable for the law to require sprinklers as long as the enforcement cost would not exceed \$1,000 per restaurant.

Society is presumed to have two alternative legal instruments for achieving use of precautions, namely, regulation and the negligence rule, and they are employed at different times.

Regulation applies at time 1, a time at which an injurer has either taken a required precaution or has not, but before an accident has had a chance to occur. Under regulation, the regulator checks to verify whether the required precaution has been taken. If it has been, that is the end of the matter; but if the precaution has not been taken, a monetary sanction for noncompliance is imposed.

The negligence rule applies only at time 2, a time by which an accident resulting in harm has had a chance to occur. Under the negligence rule, a suit may be brought provided that harm has occurred. If a suit is brought, a court will verify whether a required precaution was taken. If the precaution was taken, the injurer will be found nonnegligent; but if the precaution was not taken, the injurer will be found liable for negligence and will pay damages equal to the harm caused. Thus, if a sprinkler system is a required precaution but a restaurant did not install sprinklers and a fire occurred as a result, the restaurant could be sued and made to pay damages of $\$ 100,000$.

Regulation and the negligence rule are assumed to be essentially identical law enforcement instruments, except for the fact that regulation at applies at time 1, whereas the negligence rule applies at time 2 only if harm occurs. In particular, I assume that each legal instrument operates free of error-the regulator and the court make perfect determinations of whether precautions were taken. I also assume that each instrument involves the same enforcement cost per instance of verification that a precaution was taken $^{13}$ and that this enforcement cost is borne by the state. ${ }^{14}$

\footnotetext{
${ }^{12}$ As illustrated, the expected harm means probability-discounted harm. For analytical convenience, I assume that society and injurers are risk neutral: they evaluate risky prospects in terms of their expected values rather than in a more complicated manner reflecting risk aversion. On the concepts of risk neutrality and risk aversion, see, for example, Pindyck and Rubinfeld (2009, pp. 165-170) and Shavell (1987, chap. 8).

13 This simplifying assumption about costs may not hold in fact. For example, it could be difficult to ascertain whether a precaution was taken after harm occurred because an accident might destroy relevant
} 
Let me now compare regulation and liability, first considering the case in which enforcement is certain and then the case in which enforcement is probabilistic.

\subsection{Certain Enforcement}

I here suppose that regulation is enforced with certainty in the sense that compliance with a required precaution is checked for sure. Thus, whether a restaurant has installed a sprinkler system is definitely verified at time $1 .{ }^{15}$ The motivation for examining this case is both expositional convenience and that the case is sometimes descriptive of reality.

Because regulatory compliance is investigated with probability one, compliance can be induced as long as the sanction for noncompliance exceeds the cost of the required precaution. In the example of the sprinkler system, a restaurant will be led to meet the installation mandate as long as the sanction for failure to do so exceeds the $\$ 2,000$ cost of the system. I assume that sanctions are at least equal to the cost of compliance and that injurers' assets are sufficient to pay such sanctions; hence, injurers will comply with a regulatory requirement to take a precaution.

Further, because compliance will be checked with certainty, the enforcement cost of verifying the taking of precautions will be borne with certainty. Thus, if the cost of verifying that a sprinkler system is installed is $\$ 500$, this amount will be the cost of enforcement of regulation per restaurant. Note that if $\$ 500$ is the enforcement cost, regulation of the use of sprinkler systems will be worthwhile, for the benefit of a sprinkler system is $\$ 3,000$, whereas total costs will be less, $\$ 2,500$ - the sum of the $\$ 2,000$ cost of a system and the $\$ 500$ enforcement cost. More generally, if the cost of determining the presence of a sprinkler system is less than $\$ 1,000$, it will be worthwhile

evidence. The enforcement cost advantage of the negligence rule that I demonstrate here would obviously be reduced to the extent that the cost of determining a precaution is higher after an accident than before.

${ }^{14}$ Were I to allow for the bearing of costs by private parties in connection with law enforcement, I would have to analyze the private versus the social incentive to bring suit, among other issues. This would make the playing field for the comparison of negligence and regulation unlevel and introduce complications into the analysis that are distracting for my purposes.

${ }^{15}$ In reality, regulators would want to verify not only that a sprinkler system had been installed but also that it is functional. Hence, the interpretation of "checked for sure" might be checked for sure every time period, such as every year. 
regulating sprinkler systems; but if the verification cost exceeds $\$ 1,000$, regulation will not be worthwhile, for the cost of a system plus the enforcement cost will exceed $\$ 3,000$.

Under the negligence rule, suppose here that there will be a suit and compliance will be assessed by the court whenever harm occurs. This implies that restaurants will be induced to install sprinkler systems. In particular, if a restaurant does not install a system, there will be a $4 \%$ chance of harm, in which case the restaurant will be found liable and have to pay damages of $\$ 100,000$; thus its expected liability expense will be $\$ 4,000$. If a restaurant does install a system, its expense will be only $\$ 2,000$. Hence, the restaurant will install the system. More generally, an injurer will always be led to take a required precaution under the negligence rule, provided that, as in the sprinkler example, the benefit of the precaution exceeds its cost, ${ }^{16}$ and provided also that the injurer has sufficient assets to pay for the harm, something that I assume is true. ${ }^{17}$

The enforcement cost of obtaining compliance under the negligence rule is incurred only when harm occurs. In the sprinkler system example, the enforcement cost is incurred with only a 1\% probability, and the expected enforcement cost per restaurant is thus only $1 \% \mathrm{x} \$ 500$ or $\$ 5$. Note that the relevant probability of the bearing of the enforcement cost is the probability of a fire given that the sprinkler system is installedthe probability is $1 \%$, not $4 \%$. In other words, the very success of the negligence rule in inducing compliance lowers the expected cost of checking compliance. Observe too that the cost of checking compliance can be quite high and still the negligence rule will be worth employing. As long as the expected cost of checking compliance is less than $\$ 1,000$, which is to say, as long as the actual cost of checking compliance is less than $\$ 100,000$, the negligence rule will be worthwhile employing (for $1 \% \times \$ 100,000=$ $\$ 1,000)$.

\footnotetext{
${ }^{16}$ Let $p_{1}$ designate the probability of harm $h$ if the precaution is taken and $p_{2}$ the (higher) probability of harm if the precaution is not taken. The benefit of the precaution is thus the reduction in expected harm due to the precaution, $p_{2} h-p_{1} h$. Assume that this benefit exceeds the cost of the precaution $c$. To show that an injurer would be induced to take the precaution if required under the negligence rule, observe that if the injurer takes the precaution, his expense is $c$, whereas if he does not, his expected liability is $p_{2} h$. But $p_{2} h \geq p_{2} h-p_{1} h>c$, so that it is better for him to spend $c$ than not. This standard argument was originally made by Brown (1973).

${ }^{17}$ But see my remarks in Section 4 on the judgment proof problem.
} 
We can summarize the comparison of enforcement costs under regulation and under the negligence rule with two general statements. ${ }^{18}$

First, if it is desirable to require a precaution under both regulation and the negligence rule, then the enforcement cost per injurer will be lower under the negligence rule. Specifically, under regulation, the enforcement cost will equal the cost of verification, whereas under the negligence rule the enforcement cost will equal only an expected value: the cost of verification discounted by the probability of an accident given that the precaution is taken. ${ }^{19}$

Second, and following from the first point, if it is desirable to require a precaution under regulation, it must also be desirable to require the precaution under the negligence rule, but it may be undesirable to require the precaution under regulation yet to require it under the negligence rule. We saw this in the sprinkler example, where regulation is desirable to employ if the cost of verification is less than $\$ 1,000$, and where the negligence rule is desirable to employ if the cost of verification is less than $\$ 100,000$. Hence, if the cost of verification is between $\$ 1,000$ and $\$ 100,000$, it is desirable to employ the negligence rule to induce the use of sprinkler systems but not desirable to employ regulation.

\subsection{Probabilistic Enforcement}

I now assume that regulation is enforced probabilistically, such as that restaurants are inspected on a random basis for compliance with a requirement that they have installed sprinkler systems. The reason for studying this case is not only that regulation is in fact often enforced probabilistically. It is also that one might suspect that the enforcement cost advantage of negligence over regulation just discussed in Section 2.1 does not exist if regulation is enforced only with a probability, for that allows savings of

\footnotetext{
${ }^{18}$ These statements also essentially describe the comparison of enforcement costs in the next section with probabilistic enforcement of regulation.

${ }^{19}$ Note this point implies that the expected enforcement cost under the negligence rule could well be lower than the enforcement cost under regulation even if the verification cost per instance of use of the negligence rule exceeds that per instance of use of regulation. In the sprinkler system example, if the cost of verification under the negligence rule were $\$ 5,000$ rather than $\$ 500$, then the expected enforcement cost under the negligence rule would be $1 \% \mathrm{x} \$ 5,000$ or $\$ 50$, which is less than the $\$ 500$ cost under regulation.
} 
enforcement costs. However, as I stated in the introduction, the negligence rule still holds an advantage over regulation in the present case.

Let us first consider the achievement of compliance under probabilistic enforcement of regulation. An injurer will comply and take the required precaution as long as the expected sanction for noncompliance-the probability of being checked multiplied by the sanction for noncompliance-is high enough to outweigh the cost of the precaution. Thus, a restaurant will install a sprinkler system provided that the expected sanction for not doing so exceeds the $\$ 2,000$ cost of the system. Suppose, for instance, that the probability of monitoring compliance is $50 \%$ and that the sanction for noncompliance is $\$ 100,000$. Then the expected sanction for noncompliance would be $\$ 50,000$, which greatly exceeds the $\$ 2,000$ cost of the sprinkler system, so the restaurant would comply with the regulation. Indeed, as long as the probability of monitoring is at least $2 \%$, the expected sanction would be at least \$2,000 and compliance would be induced. In saying this, I am presuming that the sanction for noncompliance is $\$ 100,000$; the motivation for this assumption is that the sanction available to the state under regulation should be the same as it is under the negligence rule for the two instruments to be on a level playing field. ${ }^{20}$

The cost of obtaining compliance under probabilistic enforcement of regulation is now an expected cost, the probability of monitoring compliance multiplied by its cost. Hence, it is optimal for a regulator to employ the minimum probability of monitoring that will induce compliance; that will minimize the expected costs of enforcement. In the example, the minimum probability is $2 \%$, as stated in the last paragraph, for then the expected sanction for noncompliance will just equal the $\$ 2,000$ cost of the sprinkler system and just induce compliance. At a $2 \%$ probability of monitoring, the expected cost of enforcement per restaurant will be $2 \%$ x $\$ 500$ or $\$ 10$. Moreover, regulation will clearly be worthwhile enforcing at this expected cost, since the benefit of the sprinkler system is $\$ 3,000$, its cost is $\$ 2,000$, and the expected enforcement cost is only $\$ 10$. As

${ }^{20}$ Nevertheless, the argument that I am about to make demonstrating the superiority of the negligence rule does not depend on the assumption that the sanction under regulation is $\$ 100,000$ rather than some other, higher figure. As long as the maximum sanction available for use under regulation equals the sanction available under the negligence rule, and is at least equal to the harm, the conclusion about the superiority of the negligence rule holds. See Remark (b) following Proposition 4 on this point. 
long as the enforcement cost per instance of checking compliance is less than $\$ 50,000$, regulation will be worthwhile undertaking, for at $\$ 50,000$, the expected cost would be $2 \%$ $\mathrm{x} \$ 50,000$ or $\$ 1,000$, so that the cost of the precaution of $\$ 2,000$ plus $\$ 1,000$ would just equal the benefit of $\$ 3,000$ of the precaution.

Next let us again consider the negligence rule. As I explained in Section 2.1, we obtain compliance under the rule if, whenever there is an accident, there is a suit and a court inspects the behavior of the injurer to see if he was negligent. In the case of the sprinkler system, this meant that there would be checking of compliance with a $1 \%$ probability, and thus that the expected enforcement cost would be only 1\% x $\$ 500$ or $\$ 5$. Thus, the enforcement cost under the negligence rule is lower than the $\$ 10$ cost under regulation, despite the use of the minimum probability of checking under regulation. The advantage of the negligence rule is less than before, due to the use of probabilistic enforcement of regulation, but it still exists. This diminished advantage of the negligence rule is also reflected in the point that now the region of costs of checking compliance under which it would be desirable to employ the negligence rule but not regulation is from $\$ 50,000$ to $\$ 100,000$, rather than, as before, from $\$ 1,000$ to $\$ 100,000$.

But why does the negligence rule retain its enforcement cost advantage when regulation is probabilistically enforced? We can see that that is true in the example of the sprinkler system, but is this result an artifact of the particular numbers that I chose for the example? We need to understand the intuition behind the conclusion in the example before we can accept it.

The source of the advantage of the negligence rule can be appreciated by reviewing the calculus of a restaurant under regulation and under the negligence rule. Under regulation with a probability of inspection of $2 \%$, the expected sanction that a restaurant will bear if it does not install a sprinkler system will be $2 \%$ x $\$ 100,000$ or $\$ 2,000$, so it will just be induced to install it. Further, if the probability of inspection is any lower than $2 \%$, such as $1 \%$, a restaurant will not be led to install the sprinkler system (at $1 \%$, the expected sanction for failing to install the system would be only $\$ 1,000$, half of the $\$ 2,000$ cost of the system).

How is it that even though, under regulation, a $1 \%$ chance of inspection will not lead to compliance with the sprinkler requirement, under the negligence rule, a $1 \%$ 
chance of inspection will lead to compliance with the sprinkler requirement? The answer is that under the negligence rule, if the sprinkler system is not installed, the probability of inspection will be higher than $1 \%$-it will be $4 \%$, because the accident probability will rise, meaning that the expected sanction will be $\$ 4,000$, which exceeds the $\$ 2,000$ cost of the system. In other words, the way that the incentive to take a required precaution works under the negligence rule is that the probability of the sanction increases if the injurer fails to take the precaution. That threat leads the injurer to take the precaution, and because of the success of the threat, the actual frequency of checking is lower (and as I remarked above, could be zero-if it were the case that the precaution eliminated the chance of an accident). In contrast, under regulation the fact that inspection with a $2 \%$ probability induces injurers to take the precaution of installing the sprinkler system does not itself lower the likelihood of inspection; that likelihood is fixed. In summary, the reason that the negligence rule enjoys an enforcement cost advantage can be stated in two closely-related ways: the taking of a required precaution lowers the probability of costly monitoring of compliance with the rule; and because the failure to take a required precaution raises the probability of monitoring, the negligence rule achieves compliance through a threat of what the probability of monitoring would be, rather than through the actual probability of monitoring.

At this point, I hope that I have conveyed the essence of the logic of the advantage of the negligence rule over regulation even when enforcement of regulation is probabilistic, but there is a remaining issue to be considered. In the example, the probability of assessing behavior under the negligence rule was $1 \%$, which was less than the $2 \%$ minimum probability needed to obtain compliance under regulation. Yet what if the probability of assessing behavior under the negligence rule had been higher than $2 \%$ instead of being lower? This could be so in a modified example and thus it would seem that under the negligence rule the probability of evaluation of behavior could be greater than under regulation. Suppose, for instance, that we alter the example such that the probability of a fire in the absence of a sprinkler system is $8 \%$ and that the probability of a fire is $5 \%$ in the presence of a system. In this changed example, as in the original version, the effect of the sprinkler system will be to reduce the probability of a fire by $3 \%$, so that its expected value will remain equal to $\$ 3,000$. But now the probability of 
checking the behavior of a restaurant under the negligence rule will be $5 \%$, exceeding the probability of $2 \%$ under regulation. Does this mean that the negligence rule no longer possesses an enforcement cost advantage over regulation?

The answer is no, once we permit the negligence rule to be applied probabilistically, just as we have allowed regulation to be applied probabilistically. (Otherwise the comparison between regulation and the negligence rule would be biased, as it would arbitrarily constrain the negligence rule.) The interpretation of a probabilistically applied negligence rule is that if harm occurs, there is a probability rather than a certainty of suit. Suit might not be brought even though an injurer has caused harm occurs for many reasons, such as a victim's difficulty in obtaining the evidence needed to establish liability and to prove damages. Moreover, the probability of suit can in principle be controlled by the state, as fees for bringing suit, evidentiary rules, and the like are chosen by it. ${ }^{21}$

I will now demonstrate why, if the negligence rule is probabilistically enforced, it is less expensive to induce a required precaution under that rule than under probabilistically enforced regulation. Let me do this using the modified example. Suppose that the probability of suit conditional on the occurrence of harm is $25 \%$. This probability was chosen so that, if a restaurant is negligent, the unconditional probability of suit will equal $2 \%$, namely, the probability of being checked for compliance under regulation (note that $25 \%$ x $8 \%$ does equal $2 \%$ ). Therefore, if a restaurant does not install the sprinkler system, it will face an expected sanction of $2 \%$ x $\$ 100,000$ or $\$ 2,000$, so it will just be induced to install the system. And since the restaurant will install the system, the actual probability of a fire will be only $5 \%$. Consequently, the true probability of suit will be only $25 \%$ x $5 \%$ or $1.25 \%$. Since $1.25 \%$ is less than $2 \%$, the negligence rule will be less expensive to enforce than regulation, as I claimed.

The reasoning just employed applies generally and shows that no matter what the numbers may be, the probabilistically applied negligence rule holds an enforcement cost

${ }^{21}$ The argument that I am about to describe presumes that the state is freely able to choose the probability of suit. 
advantage over probabilistically employed regulation. ${ }^{22}$ In many circumstances, however, as in the original version of the example, the likelihood of an accident will be sufficiently low that the negligence rule without probabilistic application will be cheaper than probabilistically employed regulation.

\section{Formal Analysis of the Model}

Consider here the standard model of accidents, ${ }^{23}$ in which risk neutral, identical injurers can exercise care to lower the risk of harmful events. Let

$$
\begin{aligned}
& x=\text { level and cost of care, } x \geq 0 ; \\
& p(x)=\text { probability of harm; } 0<p(x)<1 ; p^{\prime}(x)<0, p^{\prime \prime}(x)>0 ; \\
& h=\text { harm if an accident occurs, } h>0 .
\end{aligned}
$$

The social objective is to minimize social costs, which, in the absence of enforcement costs (to be described), are

(1) $x+p(x) h$.

Let the $x$ that minimizes (1) be denoted $x^{*}(h)$. Assume that $h$ is large enough that $x^{*}(h)$ is positive, ${ }^{24}$ so that it is determined by

(2) $\quad p^{\prime}(x) h=-1$.

More generally, let $x^{*}(z)$ denote the $x$ that minimizes $x+p(x) z$ for any $z$. Observe that $x^{*}(z)$ is increasing in $z$ where $x^{*}(z)$ is positive. ${ }^{25}$

In the absence of any legal control over care, injurers will choose $x=0$, for exercising care is costly to them.

${ }^{22}$ The general proof is given in Section 3.2, but a demonstration in the simple context of this section in which there is a single type of precaution may be helpful. Let me use the notation from note 16. The minimum probability needed to induce compliance with regulation is $q_{R}=c / h$, for at this $q_{R}$, the expected sanction for noncompliance is $(c / h) h=c$. Now under the negligence rule, let $q_{N}$ denote the probability of suit conditional on the occurrence of harm, and choose $q_{N}$ so that it satisfies $q_{N} p_{2}=c / h$. It follows that compliance will just be induced under the negligence rule: if the injurer does not take the precaution, his expected sanction will be $q_{N} p_{2} h=(c / h) h=c$, so he will be just led to spend $c$. Therefore, the actual probability of checking compliance under the negligence rule will be $q_{N} p_{1}<q_{N} p_{2}=c / h=q_{R}$.

${ }^{23}$ See Brown (1973) and, for example, Landes and Posner (1987) and Shavell (1987).

${ }^{24}$ Since (1) is convex in $x, x^{*}(h)>0$ if and only if $1+p^{\prime}(0) h<0$, that is, if and only if $h>-1 / p^{\prime}(0)$.

${ }^{25}$ Implicit differentiation of the first-order condition determining $x^{*}(z)$, namely, $1+p^{\prime}(x) z=0$, gives $p^{\prime \prime}(x) x^{\prime}(z) z+p^{\prime}(x)=0$, or $x^{\prime}(z)=-p^{\prime}(x) /\left(p^{\prime \prime}(x) z\right)>0$. 
The state can seek to control care under regulation, by which is meant a rule prescribing a positive level of care as a standard and imposing a sanction if the standard is not met. Let

$$
\begin{aligned}
& x_{s}=\text { standard of care; } x_{s} \geq 0 ; \\
& s=\text { sanction if } x<x_{s} ; s \geq 0 ; \\
& a=\text { assets of injurers. }
\end{aligned}
$$

If $x_{s}>0$, I will say that there is regulation, whereas if $x_{s}=0$, I will say that there is no regulation. I will assume that $a>h$. I will also assume that sanctions are feasible if $a \geq$ s. ${ }^{26}$

The state can also seek to control care under the negligence rule, by which is meant a rule prescribing a positive level of care as a standard (possibly different from the regulatory standard) and imposing a sanction equal to the harm $h$ if harm occurs and the standard was not met. If $x_{s}=0$, I will say that the negligence rule is not applied.

When the state observes $x$ under either regulation or the negligence rule, it bears an enforcement cost; let

$$
k=\text { cost to the state of observing and verifying } x ; k>0 \text {. }
$$

For simplicity, I assume that individuals bear no costs associated with enforcement (other than possible sanctions) under regulation and liability.

The social objective is to minimize total social costs, that is, costs of care, $x$, plus expected harm, $p(x) h$, plus expected enforcement costs. The socially optimal $x_{S}$ will generally be denoted $x_{s}{ }^{*}$. Let me now describe the use of regulation and the negligence rule and why the negligence rule is superior to regulation.

\subsection{Certain Enforcement}

Regulation is enforced with certainty. Assume here that if the regulator chooses $x_{s}>0$, he will observe $x$ with certainty and thus will incur $k$ with certainty. Hence, social costs will be

$$
\text { (3) } x_{s}+p\left(x_{s}\right) h+k
$$

${ }^{26}$ This assumption is appropriate when care $x$ is interpreted as nonmonetary effort, for then taking care of $x$ still leaves an injurer with assets of $a$, so that he can pay a sanction of $a$. If care is interpreted as a monetary expense, then the assets that an injurer would have available to pay as a sanction would be only $a$ $-x$. This latter case is more complicated, for the most part only notationally, so that I will not formally consider it, even though the main conclusions applying to it would be the same as I will draw. 
presuming that $x_{s}$ is induced. If the regulator chooses $x_{s}=0$ - that is, there is no regulation-social costs will be

(4) $p(0) h$,

for $x$ will not need to be observed to induce $x=0$.

I will restrict attention to $x_{s}$ that can be induced. ${ }^{27}$ An $x_{s}$ can be induced if there is a feasible $s$ such that $s \geq x_{s}$; and since $s$ can be as high as $a, x_{s}$ can be induced as long as $a$ $\geq x_{s}$. It is clear from (3) that if the optimal $x_{s}$, that is, $x_{s}{ }^{*}$, is positive, it minimizes $x_{s}+$ $p\left(x_{S}\right) h$, so it equals $x^{*}(h)$, which can be induced. ${ }^{28}$ Hence, $x_{S}^{*}=x^{*}(h)$ if and only if (5) $x^{*}(h)+p\left(x^{*}(h)\right) h+k<p(0) h$, or, equivalently, if and only if (6) $k<p(0) h-\left[x^{*}(h)+p\left(x^{*}(h)\right) h\right]$;

otherwise $x_{s}^{*}=0$. Note that the right-hand side of (6) is positive, since $x^{*}(h)$ minimizes $x$ $+p(x) h$ and is assumed to be positive. ${ }^{29}$ To summarize, we have

Proposition 1. Suppose that regulation is enforced with certainty. If it is optimal to regulate, then the optimal standard of care $x_{S}^{*}=x^{*}(h)$ and social costs are $x^{*}(h)+$ $p\left(x^{*}(h)\right) h+k$. It is optimal to regulate if and only if the cost $k$ of observing care is sufficiently low, that is, if and only if (6) holds.

Negligence is assessed whenever accidents occur. Assume here that the negligence rule is applied whenever accidents occur. Then, by well-known logic, ${ }^{30}$ if $x_{S}$ is set equal to $x^{*}(h)$, injurers will be led to choose $x^{*}(h)$. Namely, if an injurer chooses $x$ $<x^{*}(h)$, he will be liable for harm (which he can pay, since $h<a$ ), so that he will choose among such $x$ to minimize $x+p(x) h$. But $x+p(x) h>x^{*}(h)+p\left(x^{*}(h)\right) h$ for all $x<x^{*}(h)$ since $x^{*}(h)$ is optimal. Further, $x^{*}(h)+p\left(x^{*}(h)\right) h>x^{*}(h)$. Hence, $x+p(x) h>x^{*}(h)$ for all $x<x^{*}(h)$; the injurer is worse off with $x<x^{*}(h)$ than with $x^{*}(h)$. Obviously he will not choose $x>x^{*}(h)$. He will therefore choose $x^{*}(h)$.

${ }^{27}$ This assumption is without loss of generality—see Section 3.3.

${ }^{28}$ Since $x^{*}(h)<x^{*}(h)+p\left(x^{*}\right) h<0+p(0) h<h<a$, we know $x^{*}(h)$ can be induced.

${ }^{29}$ Specifically, since $x=0$ is a possible $x$ but is unequal to $x^{*}(h)$, we have $0+p(0) h>x^{*}(h)+$ $p\left(x^{*}(h)\right) h$

${ }^{30}$ See originally Brown (1973). 
If $x_{s}=x^{*}(h)$, social costs will thus be

(7) $x^{*}(h)+p\left(x^{*}(h)\right)(h+k)$,

for the cost $k$ of assessing $x$ will be borne only when accidents occur.

It follows from (7) that $x^{*}(h)$ can be achieved under the negligence rule at lower cost than under regulation, since $p\left(x^{*}(h)\right) k<k$. Hence, if regulation is optimal to employ, so will be the negligence rule and it will be superior to regulation.

It also follows from (7) that when $x_{s}=x^{*}(h)$, it will be optimal to employ the negligence rule if and only if

$$
x^{*}(h)+p\left(x^{*}(h)\right)(h+k)<p(0) h,
$$

that is, if and only if

$$
k<\left[1 / p\left(x^{*}(h)\right)\right]\left\{p(0) h-\left[x^{*}(h)+p\left(x^{*}(h)\right) h\right]\right\} .
$$

Because the right-hand side of (9) exceeds the right-hand side of (6), it will be desirable to employ the negligence rule more often than regulation.

In summary, we have

Proposition 2. Suppose that the negligence rule applies whenever accidents occur. Then the negligence rule is superior to regulation: If regulation is desirable to employ, the optimal regulatory standard of care $x^{*}(h)$ can be induced under the negligence rule but at lower social costs, $x^{*}(h)+p\left(x^{*}(h)\right)(h+k)$; and if regulation is not desirable to employ, the negligence rule may still be desirable to employ, and when so, will result in lower social costs.

Remarks. (a) It was shown that the negligence rule is superior to regulation when the standard of care under the negligence rule is $x^{*}(h)$, but the optimal standard of care $x_{s}{ }^{*}$ under the negligence rule is different from (and higher than) $x^{*}(h) .{ }^{31}$ Therefore, the advantage of the negligence rule is actually greater than was demonstrated above.

(b) It was assumed that assets $a$ exceed $h$, so that injurers can be induced to choose $x^{*}(h)$ under regulation and under the negligence rule. If, however, $a$ is sufficiently below $h$, regulation may be superior to the negligence rule. The reason is that

${ }^{31}$ Social costs under positive $x_{s}$ are $x_{s}+p\left(x_{s}\right)(h+k)$, so that $x_{s}^{*}=x^{*}(h+k)>x^{*}(h)$. It may not be possible to induce $x^{*}(h+k)$ given assets $a$, but it is readily shown that even given assets of $h$, it is possible to induce $x>x^{*}(h)$ that is superior to $x^{*}(h)$. Specifically, the derivative of $x_{s}+p\left(x_{s}\right)(h+k)$ with respect to $x_{s}$ is negative at $x_{s}=x^{*}(h)$, so that it is desirable to raise $x_{s}$ above $x^{*}(h)$. Now we know that if $x_{s}=x^{*}(h)$ and the sanction is $h$, the injurer is strictly better off choosing $x^{*}(h)$ than not, for $x^{*}(h)<x^{*}(h)+p\left(x^{*}(h)\right) h$. It follows by continuity that if $x_{s}$ is raised slightly above $x^{*}(h)$ and $h$ is still the sanction, the injurer will remain strictly better off choosing $x_{s}$ than being negligent. 
if $a$ is low enough, the maximum level of care that can be induced under the negligence rule will be less than is socially desirable and less than the level of care that can be induced under regulation. Specifically, under liability, the highest $x_{s}$ that can be induced is $x^{*}(a)+p\left(x^{*}(a)\right) a$, for this is the highest possible expected expense for noncompliance. ${ }^{32}$ But $x^{*}(a)+p\left(x^{*}(a)\right) a<a$, so that a higher level of care can be induced under regulation than under the negligence rule. Further, if $x^{*}(a)+p\left(x^{*}(a)\right) a<x^{*}(h)$, then it is not possible to induce optimal care under the negligence rule, whereas it is possible to induce socially superior care under regulation. Hence, certainly if $k$ is sufficiently low, regulation will be superior to liability.

\subsection{Probabilistic Enforcement}

Regulation is enforced probabilistically. Suppose now that the regulator chooses a probability with which to observe $x$; let

$q_{R}=$ probability that the regulator observes $x$.

Hence, expected social costs given $x_{s}>0$ are

(10) $x_{s}+p\left(x_{s}\right) h+q_{R} k$,

presuming that $x_{s}$ is induced. I will continue to restrict attention to $x_{s}$ that can be induced. For an injurer to be led to choose $x_{S}$, we must have $q_{R} S \geq x_{s}$, that is, the expected sanction for noncompliance must be at least the cost of compliance. Thus, the minimum $q_{R}$ that produces compliance is $x_{s} / s$. Because it is clear from (10) that the regulator would want to employ the minimum $q_{R}$ that induces $x_{s}$, the regulator will set $q_{R}$ equal to $x_{S} / s$ and also will want to use the maximum available sanction.

I will assume that the maximum available sanction is $h$, the sanction for negligence. This assumption is made in order that regulation and the negligence rule are implemented with the same enforcement tools ${ }^{33}$ — we do not want the comparison

32 If $x_{s}>x^{*}(a)+p\left(x^{*}(a)\right) a$, an injurer could be negligent, choose $x^{*}(a)$, and bear expected expenses of $x^{*}(a)+p\left(x^{*}(a)\right) a$; thus $x_{s}$ could not be induced.

33 That the level of the sanction is $h$ is not crucial. In particular, as I show in Remark (b) after Proposition 4, the comparison between regulation and the negligence rule would be essentially the same if the sanction for noncompliance is higher than $h$, as long as it is the same for regulation as for the negligence rule. 
between them to be affected by a difference in the maximum available sanction. ${ }^{34}$ Since $h$ is the maximum available sanction, the regulator will choose

(11) $q_{R}=x_{S} / h$.

Observe that increasing $x_{S}$ raises enforcement costs because it increases the probability with which observation by the regulator must occur to induce compliance. Social costs are thus

(12) $x_{s}+p\left(x_{S}\right) h+\left(x_{S} / h\right) k$.

Note that if $x_{s}=0$, (12) becomes $p(0) h$, which makes sense because when $x_{s}=0$, the probability needed to induce compliance is 0 . Let the $x_{s}$ that minimizes (12) be denoted $x_{R}{ }^{*}$. Because (12) is convex in $x_{s}, x_{R}^{*}=0$ if and only if

(13) $1+p^{\prime}(0) h+k / h \geq 0$ or $k \geq-h\left(1+p^{\prime}(0) h\right)=k^{*}>0$.

That $-h\left(1+p^{\prime}(0) h\right)>0$ follows from the assumption that $x^{*}(h)>0$. Now if $k<k^{*}$, then $x_{R}^{*}>0$ and is determined by the first-order condition

(14) $1+p^{\prime}\left(x_{s}\right) h+k / h=0$,

which implies that

(15) $x_{R}^{*}<x^{*}(h)$.

The explanation for (15) is that reducing $x_{s}$ slightly below $x^{*}(h)$ has no first-order effect on $x_{s}+p\left(x_{s}\right) h$ but does have a first-order effect in lowering the probability $x_{S} / h$ that is needed to induce $x_{s}$. We therefore have

Proposition 3. Suppose that regulation is enforced probabilistically. If it is optimal to regulate, then the optimal standard of care $x_{S}{ }^{*}=x_{R}{ }^{*}<x^{*}(h)$, where $x_{R}{ }^{*}$ is determined by (14), the probability of observation of care by the regulator is $x_{R}^{*} / h$, the sanction for noncompliance is maximal, $h$, injurers are just induced to comply with $x_{R}{ }^{*}$, and social costs are $x_{R}^{*}+p\left(x_{R}^{*}\right) h+\left(x_{R}^{*} / h\right) k$. It is optimal to regulate if and only if the cost $k$ of observing care is sufficiently low, that is, if and only if $k<k^{*}$, where $k^{*}$ is determined by (13).

Negligence is probabilistically assessed when accidents occur. Assume here that negligence is assessed with a probability if an accident occurs. Let

34 If the assumption of equal sanctions were not made, it is obvious that regulation could be better or worse than the negligence rule because of the difference in the sanctions available under the two rules. If, for instance, a very high sanction, much greater than $h$, were available to enforce regulation, then regulation could be enforced with an extremely low probability, so could be superior to the negligence rule. 
$q_{N}=$ probability that courts examine $x$ given that an accident occurs.

Because the goal is to show the superiority of the negligence rule over regulation, suppose that regulation is optimal, that is $x_{R}{ }^{*}>0$, and that the negligence standard is the optimal regulatory standard $x_{R}{ }^{*}$. Then social costs given $q_{N}$ and $x_{R}{ }^{*}$ will be (16) $x_{R}^{*}+p\left(x_{R}^{*}\right)\left(h+q_{N} k\right)$,

provided that $x_{R}{ }^{*}$ is induced, and I will restrict attention to $q_{N}$ such that $x_{R}{ }^{*}$ is induced. Denote by $q_{N}{ }^{*}$ the minimum probability that induces $x_{R}{ }^{*}$.

I now show that $q_{N} *$ is unique, positive, and determined by

$$
x^{*}\left(q_{N} h\right)+p\left(x^{*}\left(q_{N} h\right)\right) q_{N} h=x_{R}^{*} .
$$

That there is a unique positive $q_{N}{ }^{*}$ satisfying (17) is clear, for the left-hand side of (17) is 0 at $q_{N}=0$, is strictly increasing in $q_{N}$, and equals $x^{*}(h)+p\left(x^{*}(h)\right) h>x_{R}{ }^{*}$ at $q_{N}=1$.

Observe also that (17) implies that

$$
x^{*}\left(q_{N} * h\right)<x_{R}^{*}
$$

It follows that at $q_{N}{ }^{*}$, the injurer is just induced to choose $x_{R}{ }^{*}$ : if he decides to be negligent, he will choose $x^{*}\left(q_{N} * h\right)<x_{R}^{*}$, and by (17) he will bear expected costs equal to $x_{R}{ }^{*}$. It is also clear that if $q_{N}<q_{N}^{*}$, the injurer will decide to be negligent. In particular, we know that $x^{*}\left(q_{N} h\right)$ is non-decreasing in $q_{N}$ and that the left-hand side of (17) is strictly increasing in $q_{N}$. Hence, if $q_{N}<q_{N}^{*}$, we have $x^{*}\left(q_{N} h\right) \leq x^{*}\left(q_{N}{ }^{*} h\right)<x_{R}{ }^{*}$ and

$$
x^{*}\left(q_{N} h\right)+p\left(x^{*}\left(q_{N} h\right)\right) q_{N} h<x^{*}\left(q_{N}^{*} h\right)+p\left(x^{*}\left(q_{N} * h\right)\right) q_{N}{ }^{*} h=x_{R} *
$$

Consequently, the injurer will be better off if he is negligent and chooses $x^{*}\left(q_{N} h\right)$ than if he elects $x_{R}{ }^{*}$.

It follows that the negligence rule more cheaply induces $x_{R}{ }^{*}$ than regulation. Specifically, (17) implies that

(20) $p\left(x^{*}\left(q_{N}^{*} h\right)\right) q_{N}{ }^{*} h<x_{R}^{*}$.

We also know that

(21) $p\left(x_{R}^{*}\right)<p\left(x^{*}\left(q_{N}^{*} h\right)\right)$

since $x^{*}\left(q_{N} * h\right)<x_{R}{ }^{*}$. Further, (20) and (21) imply that

$$
p\left(x_{R}^{*}\right) q_{N} * h<x_{R}^{*} \text {. }
$$

Dividing by $h$, we obtain

$$
p\left(x_{R}^{*}\right) q_{N} *<x_{R} * / h
$$


that is, the probability of assessing negligence is less than the probability of assessing compliance under regulation. (Note that the intuition behind this result is what was explained informally in Section 2: compliance under the negligence rule is obtained by the threat of assessment of compliance with a probability $p\left(x^{*}\left(q_{N} * h\right)\right) q_{N} *$ that is based on a level of care less than the negligence standard, but the actual probability of assessment of compliance $p\left(x_{R}{ }^{*}\right) q_{N}$ is lower because it is based on the level of care equal to the negligence standard.) It follows from (23) that

$$
x_{R}^{*}+p\left(x_{R}^{*}\right) h+p\left(x_{R}^{*}\right) q_{N}{ }^{*} k<x_{R}^{*}+p\left(x_{R}^{*}\right) h+\left(x_{R}^{*} / h\right) k
$$

namely, social costs (16) under the negligence rule are less than social costs (11) under regulation. It is also clear from (24) and the above discussion that the set of $k$ for which it will be desirable to employ the negligence rule is larger than that under regulation.

In summary, we have

Proposition 4. Suppose that the negligence rule and regulation are enforced probabilistically. Then the negligence rule is superior to regulation: If regulation is desirable to employ, the optimal regulatory standard $x_{R}{ }^{*}$ can be induced under the negligence rule but at lower social costs, $x_{R}{ }^{*}+p\left(x_{R}{ }^{*}\right)\left(h+q_{N} * k\right)$ since $p\left(x_{R}{ }^{*}\right) q_{N} *<x_{R} * / h$; and if regulation is not desirable to employ, the negligence rule may still be desirable to employ, and when so, will result in lower social costs.

Remarks. (a) It may be possible to induce $x_{R}{ }^{*}$ under the negligence rule at lower cost than under regulation even if negligence is assessed with certainty when harm occurs, for $p\left(x_{R}{ }^{*}\right)<x_{R} * / h$ may hold.

(b) Proposition 4 is also valid for any sanction $s>h$ that is employed for noncompliance under both regulation and the negligence rule. To establish this, note that for such an $s$, (11) becomes $q_{R}=x_{s} / s$; (14), defining $x_{R}{ }^{*}$, becomes $1+p^{\prime}\left(x_{s}\right) h+k / s=0$, implying that $x_{R}^{*}<x^{*}(h)$; and (17), defining $q_{N}^{*}$, becomes $\left(17^{\prime}\right) \quad x^{*}\left(q_{N} s\right)+p\left(x^{*}\left(q_{N} s\right)\right) q_{N} S=x_{R}^{*}$.

This equation has a unique solution as in the proof of Proposition 4, for the left-hand side of $\left(17^{\prime}\right)$ is 0 at $q_{N}=0$, is strictly increasing in $q_{N}$, and equals $x^{*}(s)+p\left(x^{*}(s)\right) s>x_{R}{ }^{*}$ at $q_{N}$ $=1$. The latter is true because $x^{*}(s)+p\left(x^{*}(s)\right) s>x^{*}(h)+p\left(x^{*}(h)\right) h>x^{*}(h)>x_{R}{ }^{*}$. The rest of the argument proceeds as in the proof of Proposition 4 and leads to the conclusion 
that $\left.p\left(x_{R}{ }^{*}\right)\right) q_{N}{ }^{*}<x_{R}{ }^{*} / s$, implying that the cost of inducing $x_{R}{ }^{*}$ under the negligence rule is less than than under regulation.

(c) Proposition 4 does not hold for s sufficiently below $h$. The explanation is essentially that given in Remark (b) following Proposition 2.

\subsection{Comment on the Assumption that Compliance is Induced}

I restricted attention in the analysis to standards $x_{s}$ that are induced. This was a natural assumption to make, but it is worth pointing out that if the assumption were not made, the outcome would not be superior-achievable social costs would not be lower. The essential reason is as follows. Suppose that the optimal standard is $x_{s}{ }^{*}$ and that it is not induced, so that injurers instead choose some lower $x^{\prime}$. Then if $x_{s}=x^{\prime}, x_{s}$ will be complied with and social costs will be less than or equal to those under $x_{s}{ }^{*}$. Hence, no advantage could have been secured by using $x_{s}{ }^{*}$ as the standard, implying that we can restrict attention to standards that are induced.

To be specific, consider the case where regulation is enforced with certainty and suppose that compliance is not induced at $x_{s}{ }^{*}$. Then injurers will clearly choose $x=0$. Also, since $x_{s} *$ must be positive for there to be noncompliance, social costs must be $p(0) h$ $+k$ under $x_{s}^{*}$. But social costs are lower if $x_{s}=0$, namely, $p(0) h$, and there is trivially compliance with this standard. Hence, $x_{s}{ }^{*}$ could not have been optimal, so we can restrict attention to $x_{s}$ that are induced.

Next consider the case where negligence is assessed whenever accidents occur and suppose that compliance is not induced at $x_{S}{ }^{*}$. Since injurers choose $x<x_{S}{ }^{*}$, they choose $x$ to minimize $x+p(x) h$, which is to say, they choose $x^{*}(h)$, so that social costs are $x^{*}(h)+p\left(x^{*}(h)\right)(h+k)$. But this outcome can be achieved when $x_{s}=x^{*}(h)$, which is an $x_{s}$ that is induced. Therefore, $x_{s}{ }^{*}$ could not have resulted in lower costs than an $x_{s}$ that is induced.

Analogous arguments apply in the cases where enforcement is probabilistic.

\section{Discussion}

I here discuss a number of issues relating to the interpretation of the analysis of the model.

The consistency of theory and actuality - the negligence determination is in fact generally more detailed than the regulatory. The theoretical conclusions reached in the 
model suggest that the negligence rule should be employed to control risks more comprehensively than regulation. Indeed, because it was shown that the expected enforcement cost of controlling a precaution under the negligence rule is lower than the expected enforcement cost under regulation, in strict logic it is always better to utilize the negligence rule to induce a precaution in the world of the model. ${ }^{35}$ The essence of the argument was, of course, that the frequency with which the taking of a precaution is, or must be, assessed in order to induce it is lower under the negligence rule than under regulation.

Reality seems broadly consistent with theory in the sense that negligence determinations are usually concerned with a wider spectrum of behavior than determinations of regulatory compliance. A negligence determination can in principle address any type of precaution, for the failure to take any action that would have lowered expected harm by more than its cost constitutes negligence - the precise description of a risk-reducing action does not matter. ${ }^{36}$ In contrast, regulation does not generally mandate the taking of any precaution that would have lowered expected harm by more than its cost, but rather usually requires the taking of only a specific list of precautions (even if a long list). ${ }^{37}$ Thus, whether a restaurant placed paper decorations at a special event too

\footnotetext{
${ }^{35}$ Why this implication does not hold if certain assumptions made in the analysis are relaxed is discussed shortly below.

${ }^{36}$ This point is reflected in the definition given by Learned Hand of the duty of care that must be taken to avoid a finding of negligence: "[T] $]$ he . . . duty, as in other similar situations, to provide against resulting injuries is a function of three variables: (1) The probability that [the harmful act will occur]; (2) the gravity of the resulting injury, if [it] does; (3) the burden of adequate precautions. . . . [I]f the probability be called P; the injury, L; and the burden, B; liability depends upon whether B is less than L multiplied by P: i.e., whether B less than PL.” United States v. Carroll Towing Co., 159 F.2d 169, 174 (2d Cir. 1947). See also RESTATEMENT (THIRD) OF TORTS $\$ 3$ (2010), stating that "[a] person acts negligently if the person does not exercise reasonable care under all the circumstances. Primary factors to consider in ascertaining whether the person's conduct lacks reasonable care are the foreseeable likelihood that the person's conduct will result in harm, the foreseeable severity of any harm that may ensue, and the burden of precautions to eliminate or reduce the risk of harm.”

${ }^{37}$ For example, a Florida statute addressing barriers that must surround residential swimming pools lists lists eight specific requirements. See Florida Statutes Annotated, Chapter 515.29. Another example is the New York City Fire Code that sets out a list of hundreds of mandated precautions. See www.nyc.gov/html/fdny/pdf/firecode/2009/fire_code_ll26_2008_amended_ll37_41_64_2009_final_compl ete.pdf. Although the fire code is lengthy, it does not cover all forms of negligence in relation to fire, for $\S$ 101.3 reads "Intent. The purpose of this code is to establish reasonable minimum requirements and standards for life safety and property protection...." However, a qualification to the statement that regulations contain only lists of specific precautions is that some regulations include open-ended standards. Driving regulations, for instance, often forbid reckless driving, which in theory might include a broad
} 
close to high-temperature halogen lamps would presumably be considered in a negligence determination if the decorations caught fire and caused harm, but the particular matter of the proximity of halogen lamps to paper decorations might not be covered by fire safety regulations. ${ }^{38}$ To express the point under discussion somewhat differently, regulation ordinarily sets only minimum standards of required behavior, so that satisfaction of regulation does not insulate a person from liability for negligence. ${ }^{39}$

Regulatory enforcement triggered by the occurrence of harm. Although I have characterized regulation as enforced independently of the occurrence of harm, this is only a central tendency, for adverse events may attract the attention of regulators and result in investigation of compliance. A fire, a crash, or an oil spill, for example, may lead regulators to inquire whether safety rules were violated. That regulation may be enforced in this manner is consistent with the theory developed here, for the costliness of regulatory enforcement explains why regulators do not examine compliance with certainty, meaning that if an accident occurs, regulators often will not have determined whether the injurer was in compliance. Furthermore, regulators will then have an affirmative reason to investigate compliance, because the occurrence of an accident is a signal that the injurer was not in compliance. Additionally, to the degree that regulated parties anticipate that their compliance will be checked if there is an accident, their incentives to satisfy regulation will resemble those that I associated with the negligence rule.

Is the analysis intrinsically addressed to regulation versus negligence or instead to ex ante versus ex post control of behavior? The observations of the preceding paragraph, that regulation is in fact not purely ex ante nature in nature, reflect the point

spectrum of negligent driving behavior. The New York traffic laws state that "Reckless driving shall mean driving ... in a manner which unreasonably interferes with the free and proper use of the public highway, or unreasonably endangers users of the public highway. Reckless driving is prohibited.” See MCKINNEY'S Consolidated LAws of NEW YoRK AnNOTATED, Vehicle AND TRAFFIC LAWS, §1212 Reckless Driving. To the extent that such standards are enforced, regulation becomes more expansive.

38 The New York City Fire Code does not appear to apply to the proximity of halogen lamps to paper decorations. It addresses in § 308.3 .3 only the risks of the proximity of open flames to decorations it says "Separation from combustibles. Open flames shall be kept at a safe distance from decorations. . ..”

39 See RESTATEMENT (THIRD) OF TORTS § 16 (2010), stating that “[a]n actor's compliance with a pertinent statute, while evidence of nonnegligence, does not preclude a finding that the actor is negligent under $\S 3$ for failing to adopt precautions in addition to those mandated by the statute.” 
that the main analytical conclusion of this article is at root not one about regulation versus the negligence rule but rather about ex ante versus ex post (triggered-by-harm) modes of inducing desired behavior. The ex post mode need not be the negligence rule of tort law; it could also be regulatory enforcement that occurs after a harmful event, resulting in a fine or a criminal sanction rather than a payment of damages to the injured party.

Qualifications to the theory-and why regulation may possess advantages over the negligence rule. A factor that was not included in the model and that works against the negligence rule is difficulty in proving causation, for this dilutes the threat of liability but does not affect regulation. If it would be a problem to establish that an injurer caused harm (for instance, a pollution-related harm), the likelihood of liability for negligence would be reduced, but this point would be irrelevant for regulatory enforcement.

Another omitted factor weighing against the negligence rule is the judgment proof problem because it too dilutes the threat of liability. However, the judgment proof problem could also interfere with regulatory enforcement, as it can diminish the threat of a sanction for noncompliance with regulation. Nevertheless, the judgment proof problem impinges more on the effectiveness of the negligence rule and may make regulation the superior instrument of control. ${ }^{40}$

A third excluded factor that might be thought to favor regulation is the expertise of regulators. It is natural to believe that regulators have more knowledge about their areas of risk than do generalist courts, for example, that the Environmental Protection Agency possesses more knowledge of environmental risks than courts. If so, regulators would be better able to identify worthwhile precautions than courts. This line of argument does not necessarily lead to the conclusion that regulation is superior to the negligence rule, however. If regulators have superior information allowing them to

${ }^{40}$ To illustrate, in the example of the sprinkler systems, suppose that the assets of a restaurant are $\$ 10,000$. Then it is clearly possible to induce the use of a sprinkler system, for its cost is $\$ 3,000$ : Any sanction between $\$ 3,000$ and $\$ 10,000$ is feasible and will lead to use of a system if regulation is enforced with certainty; and the highest feasible sanction of $\$ 10,000$ will lead to use of a system as long as the probability of regulatory enforcement is at least $30 \%$ for $30 \%$ x $\$ 10,000$ is $\$ 3,000$. However, use of the sprinkler system will not be induced under the negligence rule. For if a restaurant owner does not install a system, his expected liability will be $4 \%$ x $\$ 10,000$ or $\$ 400$, which is much less than its $\$ 3,000$ cost. This point is discussed in the Remark (b) following Proposition 2 and also in Shavell (1984a). 
formulate standards that are better than those the courts could determine on their own, regulators could announce their standards but leave it to the courts to enforce the standards employing the negligence rule. That is, the "regulators" would not regulate but rather advise the courts. ${ }^{41}$

Desirability of the joint use of regulation and the negligence rule. The general implication of the several preceding reasons why regulation may sometimes hold an advantage over the negligence rule is that regulation should be employed along with the negligence rule. In particular, if both instruments are utilized, then, on one hand, society will be effectively guaranteed that regulated precautions will be taken, which will be of value because in certain contexts the negligence rule will be ineffective in inducing precautions. On the other hand, society will usually be able to enjoy the savings in enforcement costs that the negligence rule yields in the control of other precautions, as explained in the analysis of the model. Thus, if both regulation and the negligence rule are used to control fire risks, society will know that regulated precautions such as installation of sprinkler systems and exit signs will be taken, even though judgment proof parties would not take these precautions if their only inducement to do so were the prospect of liability. At the same time, society will be able to obtain substantial savings in enforcement costs by controlling a large swath of unregulated fire risks through the negligence rule, which will be relevant for the many parties whose assets are not meager.

An aspect of the desirability of the joint use of regulation and the negligence rule - of the fact that parties must satisfy regulation and are subject to liability for negligence-is that satisfaction of regulation should not insulate an injurer from liability for negligence. ${ }^{42}$ One way of explaining why it can be socially advantageous to find a party negligent even though the party satisfied regulation is to point out the fallacy in a commonly made argument to the contrary. This opposing argument is that if regulation did not call for a precaution, say did not call for oily rags to be removed from storage closets where they could present a fire risk, then it must have been that regulators considered that precaution but decided not to require it (and hence why should courts

${ }^{41}$ This in fact occurs, in that violation of regulations tends to result in a finding of negligence. See RESTATEMENT (THIRD) OF TORTS $\S 14$ (2010), on statutory violations as negligence per se. However, the presumption of negligence per se may be rebutted, as discussed in $\S 15$.

\footnotetext{
${ }^{42}$ This observation is also consisent with reality, as mentioned in note 39.
} 
require it?). The error in the argument is the presumption that when regulation was formulated, regulators must have contemplated the whole menu of possible precautions and required all those worth taking. Rather, a better view, which is in a sense the central conclusion of the analysis of this article, is that it would be inefficient for regulators to address most of the multitude of precautions that might in the ideal be worthwhile controlling because inducing precautions can ordinarily be more cheaply accomplished through use of the negligence rule. Therefore, that regulation does not ask for a precaution to be taken does not mean that regulators decided that it did not need to be taken. Instead, that regulation does not require a precaution to be taken often implies that the precaution was not within their efficient ambit, because the precaution was in the vast category of precautions best left to the liability system to control.

An analogue to the enforcement cost advantage of the negligence rule over regulation: an advantage of strict liability over corrective taxation. Let me conclude by observing that there exists an enforcement cost advantage of strict liability over corrective taxation that is analogous to the enforcement cost advantage of the negligence rule over regulation studied in this article. Strict liability is, of course, the form of liability under which injurers pay for harm done, and corrective taxation is the ex ante form of control of activities under which injurers pay for the expected harm that they generate, so that it may be regarded as the ex ante cousin of strict liability.

Strict liability can be seen to require a lower probability of application than the corrective tax and thus to hold an enforcement cost advantage for reasons closely-related to those discussed in Sections 2 and 3. To illustrate, consider again the example of restaurants and sprinkler systems. Under strict liability, a restaurant must pay for harms due to fires that occur, and thus, as is readily verified, it would be induced to install a sprinkler system. Consequently, the probability of fires and of incurring enforcement costs would be only $1 \%$. Under the corrective tax that is applied with certainty, the restaurant would pay a tax of $4 \% \times \$ 100,000$ or $\$ 4,000$ if it did not install sprinklers and a tax of $1 \%$ x $\$ 100,000$ or $\$ 1,000$ if it did install sprinklers. Hence, a restaurant would be led to install the sprinklers under the tax, and enforcement costs would be borne with certainty. Thus, the tax would lead to the same outcome, installation of sprinklers, as strict liability, but it would be applied more often and thus be more expensive than strict 
liability. If the tax were applied probabilistically, then enforcement costs could be saved, but the tax would still have to be used with greater probability than strict liability and thus still involve greater enforcement costs. ${ }^{43}$

A final comment is that under the corrective tax, unlike under strict liability, the state would have to determine the precautions taken by an injurer - such as whether a sprinkler system was installed - in order to compute the expected harm. Under strict liability the authority need only determine the harm that eventuates. This suggests that the per instance cost of application of the tax might exceed that of strict liability. ${ }^{44}$ Nevertheless, if the amount of the tax is lower than the harm, there is less reason for the taxed party to resist than under strict liability, suggesting that enforcement cost of the corrective tax could be less than that of strict liability.

${ }^{43}$ If the tax $t$ is applied with probability $q_{T}$, then $q_{T} t$ must equal the expected harm. Let me assume, as I did in the analysis of Sections 2 and 3, that the maximum amount that can be collected from an injurer is the same under ex ante enforcement as under liability, and let this amount be $h$ for concreteness, which is $\$ 100,000$ in the example. Therefore, if no sprinkler system is installed, the maximum tax is $\$ 100,000$. Since this must equal the expected harm of $\$ 4,000$, the minimum probability $q$ of imposing the tax is $4 \%$. But this exceeds the probability $1 \%$ of suit under strict liability. More generally, using the notation from note 16, we must have that $q_{T} t=p_{1} h$ when care is taken and $q_{T} t=p_{2} h$ when care is not taken, for the tax must equal the expected harm. Since the maximum $t$ is $h$, and since $p_{1}<p_{2}$, the minimum $q_{T}$ satisfies $q_{T} h=p_{2} h$, so the minimum $q_{T}$ that leads to a tax equal to expected harm is $p_{2}$. But under strict liability, the probability of harm and suit is $p_{1}$ since parties are induced to take care.

${ }^{44}$ My articles Shavell $(2011,2012)$ emphasizes the problem that the state would often have in computing the corrective tax. 


\section{References}

Brown, John P. 1973. Toward an Economic Theory of Liability. Journal of Legal Studies. 2: 323-349.

Dobbs, Dan B. 2000. The Law of Torts. St. Paul: West.

Keeton, W. Page, Dan B. Dobbs, Robert E. Keeton, and David G. Owen. 1984. Prosser and Keeton on The Law of Torts, Fifth ed. St. Paul: West.

Kessler, Daniel, ed. 2011a. Regulation vs. Litigation: Perspectives from Economics and Law. Chicago: University of Chicago Press.

Kessler, Daniel. 2011b. Introduction. In Regulation vs. Litigation: Perspectives from Economics and Law. Daniel P. Kessler (ed.). Chicago: University of Chicago Press.

Kolstad, Charles D., Thomas S. Ulen, and Gary V. Johnson. 1990. Ex Post Liability for Harm vs. Ex Ante Regulation: Substitutes or Complements? American Economic Review. 80: 888-901.

Landes, William M., and Richard A. Posner. 1987. The Economic Structure of Tort Law. Cambridge, MA: Harvard University Press.

Pindyck, Robert S., and Daniel L. Rubinfeld. 2009. Microeconomics. Seventh ed. Saddle River, NJ: Prentice Hall.

Posner, Richard A. 2010. Economic Analysis of Law. Eighth ed. New York: Aspen.

Posner, Richard A. 2011. Regulation (Agencies) versus Litigation (Courts): An Analytical Framework. In Regulation vs. Litigation: Perspectives from Economics and Law. Daniel P. Kessler (ed.). Chicago: University of Chicago Press.

Shavell, Steven. 1984a. Liability for Harm versus Regulation of Safety. Journal of Legal Studies. 13: 357-374.

Shavell, Steven. 1984b. A Model of the Optimal Use of Liability and Safety Regulation. RAND Journal of Economics. 15: 271-280.

Shavell, Steven. 1987. Economic Analysis of Accident Law. Cambridge, MA: Harvard University Press.

Shavell, Steven. 2011. Corrective Taxation versus Liability. American Economic Review. 101: 273-276. 
Shavell, Steven. 2012. Corrective Taxation versus Liability as A Solution to the Problem of Harmful Externalities. Forthcoming, Journal of Law and Economics.

Shleifer, Andrei. 2011. Efficient Regulation. In Regulation vs. Litigation: Perspectives from Economics and Law. Daniel P. Kessler (ed.). Chicago: University of Chicago Press.

Wittman, Donald. 1977. Prior Regulation versus Post Liability: The Choice Between Input and Output Monitoring. Journal of Legal Studies. 6: 193-211. 